\title{
Challenges and Difficulties in Social Media Analytics
}

\author{
Mrs. T. Vamshi Mohana \\ Dept. of Computer Science, RBVRR Women's College, Narayanguda, Hyderabad
}

\begin{abstract}
Web 2.0 tools and the appearance of social media seem to have redefined the marketing strategy, research and practice, broadening marketing's potential. These potentials go beyond customers' information and expand on commitment and engagement levels. Since an ever-increasing part of the population makes use of social media in their day-to-day lives, social media data is being analyzed in many different disciplines. Social media produce a vast amount of measurable useful data to analysts and marketers whose goal is to monitor and analyze behavioral targeting, brand loyalty and further marketing performance indicators, rendering these data effective. Social media can serve as an effective marketing tool in business, valuable for both consumers and companies, offering a wide range of opportunities. Therefore, social media show an unprecedented increase of use inside business. Even though, understanding social media is a crucial, but not a simple procedure. The social media analytics process involves four distinct steps, data discovery, collection, preparation, and analysis. While there is a great deal of literature on the challenges and difficulties involving specific data analysis methods, there hardly exists research on the stages of data discovery, collection, and preparation. This study analyzes the Challenge and Difficulties in Social Media Analytics.
\end{abstract}

Keywords: Social Media Analytics, Challenge and Difficulties, Information systems, etc.

\section{INTRODUCTION}

Social media analytics "is concerned with developing and evaluating informatics tools and frameworks to collect, monitor, analyze, summarize, and visualize social media data ... to facilitate conversations and interactions ... to extract useful patterns and intelligence...".

Increasingly, the focal point of discussion of all aspects of a company's product portfolio is moving from individual company Web sites to collaborative sites, blogs and forums - collectively known as social media. In this new media essentially, anyone can post comments and opinions about companies and their products, which may influence the perceptions and purchase behavior of a large number of potential buyers. This is of obvious concern to marketing organizations - not only is the spread of negative information difficult to control, but it can be very difficult to even detect it in the large space of blogs, forums and social networking sites.

Many existing research papers are isolated case studies that collect a large data set during a specific time frame on a specific subject and analyze it quantitatively. Despite the variety of disciplines such projects can be found in, they have much in common. The steps necessary to gain useful information or even knowledge out of social media are often similar. Therefore, the field of "Social Media Analytics" aims to combine, extend, and adapt methods for the analysis of social media data. It has gained considerable attention and subsequently acceptance in academic research, but there is still a lack of comprehensive discussions of social media analytics, and of general models and approaches.

Of course, there is also research that discusses challenges researchers face when employing specific methods for analyzing social media data, such as social network analysis or opinion mining, and there are literature reviews focused on specific goals such as the identification of users who are influential offline or on specific topics such as social bots. Yet social media analytics consists of several steps, of which data analysis is only one. Before the data can be analyzed, they have to be discovered, collected, and prepared. An overview of the challenges of social media analytics is needed to be able to manage the complexity of conducting social media analytics.

\section{SOCIAL MEDIA}

Social interaction through technology and internet-based tools have collectively given birth to the term "Social Media". Wide reach and fast speed of communication are some of the important characteristics that make social media very different from other forms of communication. Interactivity is another important characteristic of social media, by which participants can freely send, receive, and process content for use by others. Services offered by the social media include: social networking, content production, video and photo sharing, chats and communities etc. People communicate on social media through social networking, which involves the use of websites or applications in order to interact with other people using the social networking sites. These people may have same interests or may know each other through other groups or communities. There are plenty of features being offered by social networking sites, which include making 


\section{International Advanced Research Journal in Science, Engineering and Technology}

Vol. 8, Issue 6, June 2021

\section{DOI: $10.17148 / / A R J S E T .2021 .8641$}

profile, finding people with mutual interests, sharing with groups, interacting with people in groups and getting the information shared by other people. Millions of people are using social media, sharing content and offering their opinions online. It is of no surprise that these tools have begun to pave their way into the professional working environment as well. Globalization, mobility and virtualization have become common trends, whereas the collaborating to make business decisions is on top priority for many companies. Social media is not just a marketing tool, but it has also given a new way for running a business effectively. As an emerging phenomenon, social media provides a platform to disseminate information about the products and services offered by organizations. It also provides a platform for conversations and attending to the customer expectations or views. Organizations could utilize the potential of social media and connect through a common social media platform, where consumers and stakeholders can collaborate and make productive decisions. However, these social media platforms are highly crowded and very competitive. That is why, it becomes essential for organizations to test and track results in order to identify the most effective strategies based on social media.

\subsection{Social media monitoring Tools}

Some popular tools for monitoring of social media are: Yomego, Ubervu, Hootsuite and Vocus. Data is visually presented using graphs and tables that can be customized through dashboards. Table 3 provides web-traffic estimation services which help gather how much traffic websites are receiving. Other tools which social media managers may find useful are given in Table 1 and 2. Table 1 lists several web analytics reporting tools which can be used for producing insights from users' own websites.

Table 2: Web analytics tools

\begin{tabular}{|c|l|}
\hline Service & \multicolumn{1}{|c|}{ Description } \\
\hline AWStats & $\begin{array}{l}\text { An open-source web analyticsreporting tool where users are encouraged to contribute to its } \\
\text { development. }\end{array}$ \\
\hline GoogleAnalytics & $\begin{array}{l}\text { Perhaps the most widely usedwebsite metrics service. It generates detailed metrics about a } \\
\text { website's traffic. It's easy to use and is specifically designed for marketing research. }\end{array}$ \\
\hline WebSTAT & $\begin{array}{l}\text { Its distinctive trait is the measureof visitors' behavior once on the website. This includes their } \\
\text { drivers and conversions; such as, the degree to which different landing pages are associated with } \\
\text { online purchases. }\end{array}$ \\
\hline Amung.us & $\begin{array}{l}\text { Provides widgets to be includedin the websites which show the number of live readers viewing a } \\
\text { webpage and the location of current and previous visitors, in real time. }\end{array}$ \\
\hline
\end{tabular}

Table 2: Web traffic estimation tools

\begin{tabular}{|c|l|}
\hline Service & \multicolumn{1}{c|}{ Description } \\
\hline Compete & Helps to monitor onlinecompetition and to benchmark performance against the industry. \\
\hline Websitetrafficspy & $\begin{array}{l}\text { Makes use of data from a numberof external sources to estimate traffic of a business' website or } \\
\text { of their competitors. }\end{array}$ \\
\hline Alexa & $\begin{array}{l}\text { Provides an estimate of thepercentage of internet users that may have visited a website during } \\
\text { the last six months and allows comparisons with other websites. }\end{array}$ \\
\hline
\end{tabular}

Though this kind of data might not be completely accurate, it can be extremely useful to get an overall picture for marketing research.

\section{SOCIAL MEDIA ANALYTICS}

From A Marketing and market intelligence perspective, blogs are a very important form of social media because they provide access to previously inaccessible information such as specific customer insights and opinions. Social media analytics can address several interesting questions by providing algorithms and approaches for the automated analysis of blogs and related social media. 


\section{DOI: 10.17148/IARJSET.2021.8641}

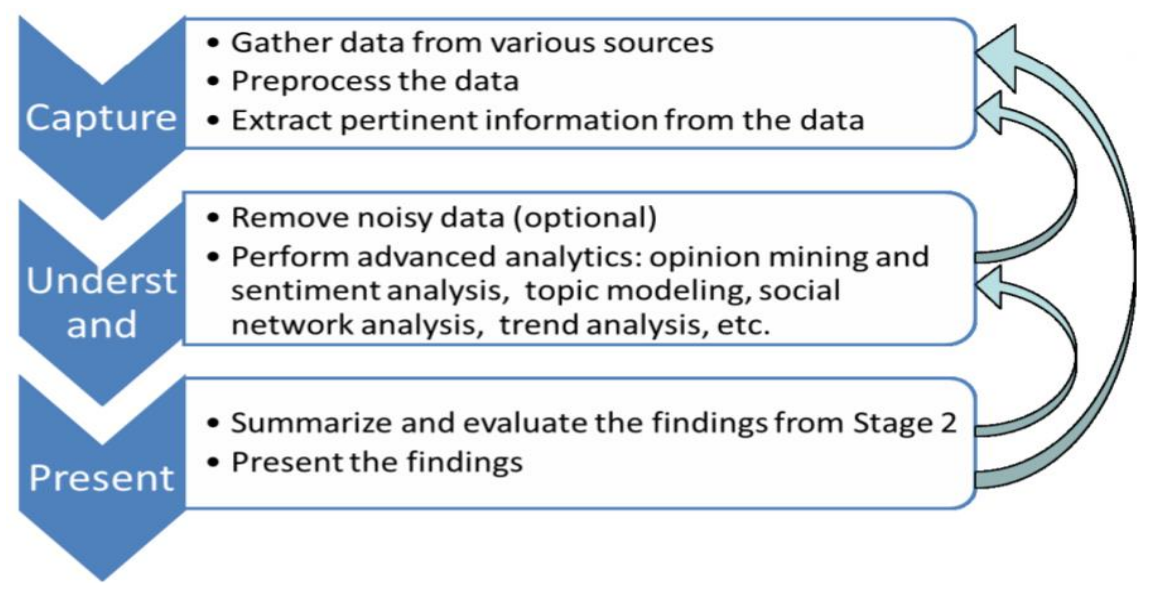

Figure 1: Social Media Analytics Process

Other drivers for Social Media Analytics are: identifying influencers; measuring effectiveness of marketing campaigns; determining brand reputation; understanding sentiments and identifying target audience. Yang and Shih (2012) offered a rule-based sentiment analysis technique to analyze customer reviews about business offerings.

Social network analysis is used to model social network dynamics and growth (network density, locations of new node attachments, etc.) that can help monitor business activity. Social network analysis is the primary technique for identifying key influencers in viral marketing campaigns on Twitter or other social media platforms. It is used to detect subcommunities within a larger online community such as a discussion forum, allowing for greater precision in tailoring products and marketing materials. It has strong used in predictive modeling, such as conducting marketing campaigns aimed at those assumed mostly likely to buy a particular product.Social network analysis is used to analyze a social network graph to understand its underlying structure, connections, and theoretical properties as well as to identify the relative importance of different nodes within the network. A social network graph consists of nodes (users) and associated relationships (depicted by edges). The relationships are typically detected from user actions directly connecting two people (such as accepting another user as a "friend"), though they may be inferred from indirect behaviors creating relationships, such as voting, tagging, or commenting.

\section{CHALLENGES IN SOCIAL MEDIA ANALYTICS}

Social media scraping and analytics provides a rich source of academic research challenges for social scientists, computer scientists and funding bodies. Challenges include:

\# Data cleansing — cleaning unstructured textual data (e.g., normalizing text), especially high-frequency streamed real-time data, still presents numerous problems and research challenges.

* Scraping - although social media data is accessible through APIs, due to the commercial value of the data, most of the major sources such as Facebook and Google are making it increasingly difficult for academics to obtain comprehensive access to their 'raw' data; very few social data sources provide affordable data offerings to academia and researchers. News services such as Thomson Reuters and Bloomberg typicallycharge a premium for access to their data. In contrast, Twitter has recently announced the Twitter Data Grants program, where researchers can apply to get access to Twitter's public tweets and historical data in order to get insights from its massive set of data (Twitter has more than 500 million tweets a day).

\# Data protection - once you have created a 'big data' resource, the data needs to be secured, ownership and IP issues resolved (i.e., storing scraped data is against most of the publishers' terms of service), and users provided with different levels of access; otherwise, users may attempt to 'suck' all the valuable data from the database.

\# Holistic data sources_researchers are increasingly bringing together and combining novel data sources: social media data, real-time market \& customer data and geospatial data for analysis.

* Data visualization-visual representation of data whereby information that has been abstracted in some schematic form with the goal of communicating information clearly and effectively through graphical means. Given the magnitude of the data involved, visualization is becoming increasingly important.

\# Analytics dashboards-many social media platforms require users to write APIs to access feeds or program analytics models in a programming language, such as Java. While reasonable for computer scientists, these skills are typically beyond most (social science) researchers. Non-programming interfaces are required for giving what might be referred to as 'deep' access to 'raw' data, for example, configuring APIs, merging social media feeds, combining holistic sources and developing analytical models. 


\section{International Advanced Research Journal in Science, Engineering and Technology}

Vol. 8, Issue 6, June 2021

\section{DOI: 10.17148/IARJSET.2021.8641}

Data analytics — sophisticated analysis of social media data for opinion mining (e.g., sentiment analysis) still raises a myriad of challenges due to foreign languages, foreign words, slang, spelling errors and the natural evolving of language.

\section{CONCLUSION}

Data is changing our world - and fast. There is no denying this fact. What we buy, what we eat, how we communicate, how we are governed, how we live are all affected by the use of data. However, it should be noted that using data in dayto-day life is not a new concept. Ancient civilizations designed their calendars by predicting planetary movements based on data from prior recordings. Organizations should plan their big data and social media policies carefully and with a long-term view in mind. Social media analytics is still a relatively new research area, but it is of great interest to the Information Systems community and many researchers are embarking on SMA projects in our field. This article contributes to the Information Systems literature by presenting a summary of the main challenges and difficulties researchers face in the steps of the social media analytics research process that come before the data is analyzed: discovery, collection and preparation. If the challenges highlighted above are addressed successfully, the social media analytics project will be much more likely to be a success.

\section{REFERENCES}

[1]. Anderson, K. M., Aydin, A. A., Barrenechea, M., Cardenas, A., Hakeem, M., \& Jambi, S. (2015). Design Challenges/Solutions for environments supporting the analysis of social media data in crisis informatics research. Proceedings of the annual Hawaii international conference on system sciences, 163-172. http://dx.doi.org/10.1109/HICSS. 2015.29.

[2]. Aral, S., Dellarocas, C., \& Godes, D. (2013). Introduction to the special Issue-Social media and business transformation: a framework for research. Information Systems Research, 24(1), 3-13. http://dx.doi.org/10.1287/isre.1120.0470.

[3]. Aral, S., Dellarocas, C., \& Godes, D. (2013). Introduction to the special Issue-Social media and business transformation: a framework for research. Information Systems Research, 24(1), 3-13. http://dx.doi.org/10.1287/isre.1120.0470

[4]. Fan, W., \& Gordon, M. D. (2014). The Power of Social Media Analytics. Commun. ACM, 57(6), 74-81. http://dx.doi.org/10.1145/2602574

[5]. Hiltz, S.R., Diaz, P., \& Mark, G. (2011). Social media and collaborative systems for crisis management, ACM Transactions on Computer-Human Interaction, Vol. 18 Issue 4, December 2011, ACM New York, NY, USA, DOI: https://doi.org/10.1145/2063231.

[6]. Reuter, T., \& Cimiano, P. (2012). Event-based classification of social media streams. In Proceedings of the 2nd ACM International Conference on Multimedia Retrieval - ICMR '12. New York, NY, USA: ACM. https://doi.org/10.1145/2324796.2324824.

[7]. Schober, M. F., Pasek, J., Guggenheim, L., Lampe, C., \& Conrad, F. G. (2016). Social Media Analyses for Social Measurement. Public Opinion Quarterly, 80(1), 180-211. http://dx.doi.org/10.1093/poq/nfv048

[8]. Shah, D. V., Cappella, J. N., \& Neuman, W. R. (2015). Big Data, Digital Media, and Computational Social Science: Possibilities and Perils. The Annals of the American Academy of Political and Social Science, 659(1), 6-13. http://dx.doi.org/10.1177/ 0002716215572084.

[9]. Stieglitz, S., Dang-Xuan, L., Bruns, A., \& Neuberger, C. (2014). Social Media Analytics - An Interdisciplinary Approach and Its Implications for Information Systems. Business \& Information Systems Engineering, 6(2), 89-96. http://dx.doi.org/10.1007/s11576- 014-0407-5

[10]. Tinati, R., Phillipe, O., Pope, C., Carr, L., \& Halford, S. (2014). Challenging Social Media Analytics: Web Science Perspectives. In Proceedings of the 2014 ACM Conference on Web Science (pp. 177-181). New York, NY, USA: ACM. https://doi.org/10.1145/ 2615569.2615690

[11]. Tsou, M.-H., Jung, C.-T., Allen, C., Yang, J.-A., Gawron, J.-M., Spitzberg, B. H., \& Han, S. (2015). Social Media Analytics and Research Testbed (SMART Dashboard). In: SMSociety '15, Proceedings of the 2015 International Conference on Social Media \& Society (2:1-2:7). New York, NY, USA: ACM. https://doi.org/10.1145/2789187. 2789196

[12]. Zeng, D., Chen, H., Lusch, R., \& Li, S. H. (2010). Social media analytics and intelligence. IEEE Intelligent Systems, $25(6)$, 13-16. http://dx.doi.org/10.1109/MIS.2010.151 